\section{Proust TRADUTOR: VISÃO E CRÍTICA}

PROUST TRANSLATOR: VISION AND CRITICISM

\section{Luciana Persice Nogueira}

Universidade Federal do Rio de Janeiro

Rio de Janeiro, RJ, Brasil

\section{Resumo}

O exame do olhar crítico sobre Proust permite dimensionar a importância estratégica das traduções feitas pelo escritor na relação com o conjunto de sua obra. Suas duas traduções, La Bible d'Amiens e Sésame et les lys - títulos de John Ruskin -, permitem-lhe combater a imagem de escritor diletante e decadentista do início de sua carreira literária. Ulteriormente, geram polêmica quanto à importância de Ruskin no seu trabalho ficcional.

\section{Résumé}

L'examen du regard critique sur Proust permet d'apprécier l'importance stratégique des traductions entreprises par l'écrivain dans le rapport avec l'ensemble de son œuvre. Ses deux traductions, $L a$ Bible d'Amiens et Sésame et les lystitres de John Ruskin -, lui permettent de combattre l'image d'écrivain dilettante et décadent du début de sa carrière littéraire. Ultérieurement, elles génèrent des polémiques quant à l'importance de Ruskin dans son travail fictionnel.

\begin{abstract}
The study of the critical views on Proust allows an appreciation of the strategic importance of the translations made by the writer, in their relationship with his other works. His two translations, $L a$ Bible d'Amiens and Sésame et les lys - books by John Ruskin -, allow him to fight the image of dilettant and decadent writer created at the beginning of his literary career. They will also generate polemics concerning Ruskin's importance in his fictional work.
\end{abstract}

PALAVRAS-CHAVE: tradução; recepção; Marcel Proust.
MOTS-CLÉS: traduction; réception; Marcel Proust

KEYWORDS: Translation, reception, Marcel Proust

Marcel Proust (1871-1922) é considerado como um dos maiores escritores da literatura. $\mathrm{O}$ caminho que leva Proust a essa estatura, porém, é sinuoso e tem um traçado, visto em retrospectiva, surpreendente, pois seus primeiros escritos não foram sequer bem recebidos pela crítica: seu primeiro título, Les Plaisirs et les Jours (1896), essencialmente uma coletânea de poemas em prosa publicados em diversas revistas literárias até então, lhe renderam a fama de pequeno diletante. Entretanto, a edição escalonada de $A$ 
la Recherche du Temps Perdu (1913-1927) lhe conferiu, progressivamente, a reputação de grande escritor. Entre ambos, Proust adquire uma voz crítica avalizada e um projeto literário amadurecido que lhe permitem avançar, tomo a tomo, contra a corrente, contra toda sorte de críticas, na construção paulatina de sua flamboiante obra catedral. Esse "entre-dois" constitui a fase das traduções, em que Proust coloca sua ficção de lado em prol da leitura, estudo, divulgação, comentário e interpretação do trabalho do esteta e pensador inglês John Ruskin (1819-1900).

O olhar crítico sobre os escritos de Proust foi expresso em todos os momentos de sua carreira, resvalou tanto sobre seus diversos títulos literários quanto suas traduções, e são um dos principais assuntos tratados ao longo de sua extensa correspondência pessoal (editada em 21 volumes pela Plon, Paris).

Essa crítica já pode ser evidenciada com o próprio fato de que é Proust quem tem que financiar os seus dois primeiros títulos, Les Plaisirs et les jours e Un Amour de Swann. O primeiro, junto à Calmann-Lévy, o segundo, à Grasset, não sem antes ter de bater à porta de cinco editoras: Figaro, Mercure de France, Fasquelle, Nouvelle Revue Française (NFR) e Olendorff.

Na busca do editor para Un Amour de Swann, alguns dos pareceres contrários à publicação se tornaram célebres: na Fasquelle, declaram: "Ao final de 712 páginas de manuscrito... depois de infinitas desolaçōes, de se afogar em insondáveis digressões e de crispantes impaciências por não se conseguir jamais retornar à superfície, não se tem nenhuma, absolutamente nenhuma noção do que está acontecendo. Por que tudo isso? O que signfica tudo isso? Aonde quer chegar tudo isso? Impossível saber. Impossível conseguir dizer o que quer que seja!"; na Ollendorff: “Talvez eu seja completamente tapado, mas não consigo entender que um homem possa levar trinta páginas descrevendo como ele vira de um lado para outro na cama antes de conseguir dormir"; e André Gide, na NRF: "Está cheio de duquesas, não é para nós"; outra versão conta que Gide sequer abriu o pacote contendo o manuscrito - justamente por causa da reputação de diletante do autor.

Há, também, os comentários aos diversos títulos ficcionais editados. Alguns deles, feitos por nomes proeminentes da literatura francesa, hoje, soam insólitos. ${ }^{1}$

\footnotetext{
${ }^{1}$ Esses e outros comentários podem ser encontrados em YVERT, Sylvie. Ceci n'est pas de la littérature: les forcenés de la critique passent à l'acte. Paris: Éd. du Rocher,
} 
Georges Bernanos: "A terrivel introspeç̧ão de Proust não leva a lugar algum."

Léon Blum (sobre Les Plaisirs et les jours): "Crônicas mundanas, estórias melosas, versos melódicos, fragmentos em que a precisão do traço se atenua na graça lânguida da frase, o Senhor Proust reuniu todos os gêneros e todos encantos. Por isso, as belas damas e as jovens lerão um livro tão belo com um prazer emocionado."

Paul Claudel: " $L i$ Le Temps Retrouvé de Proust. Assustadoramente enfadonho, quase insuportável."

Louis-Ferdinand Céline: "essas frases que mordem a própria cauda depois de intermináveis tortuosidades. Cheiram a impotência."

Anatole France: "A vida é curta demais, e Proust é longo demais"; "Não entendo nada de sua obra [...] Fiz força para compreender, mas não consegui. Mas não é culpa sua, é minha. Só compreendemos nossos próprios contemporâneos, os de nossa geração, talvez os da geração imediatamente após a nossa. Depois, acabou."; "[suas] frases intermináveis que nos deixam pneumônicos" (ainda assim, France escreveu o prefácio de Les Plaisirs et les jours).

André Gide: “Que livros curiosos! Penetramos neles como em uma floresta encantada; desde as primeiras páginas, nos perdemos e ficamos felizes de nos perdermos entre elas; logo já não sabemos por onde entramos nem a que distância estamos da clareira; a certos momentos, parece que avançamos sem caminhar; olhamos para tudo em nossa volta enquanto passamos; não sabemos mais onde estamos, aonde vamos."

Jean Lorrain: "Os senhores José-Maria de Heredia e Anatole France são mesmo os grandes culpados. Com sua condescendência de gualanthuomo [sic], escrevendo prefácios complacentes a formosos jovenzinhos da alta sociedade ansiosos por literatura e de sucesso nos saloes... Mas eis as Hortensias bleus de Montesquiou, os Plaisirs et les Joies [sic] do senhor Marcel Proust, estampados com a assinatura da Academia"; "estejam certos de que, em seu próximo volume, o senhor Marcel Proust obterá seu prefácio... do próprio intransigente senhor Alphonse Daudet, que não o poderá negar... a seu filho Lucien."2

Charles Maurras: "Não é simples louvar o senhor Marcel Proust: seu primeiro livro, esse Traité des Plaisirs et des Jours [sic], que acabou de publicar, marca uma tão extrema diversidade de talentos que ficase atrapalhado ao ter que observá-los todos, ao mesmo tempo, em um

2008; e na revista eletrônica Rivage de Bohème (rivagedeboheme.e-monsite.com/ rubrique,proust-juge-par-ses-pairs, 1580940. html). Todas as traduçôes para o português neste artigo são minhas.

${ }^{2} \mathrm{O}$ primeiro comentário foi publicado em 01/07/1896 e o segundo, em 03/02/1897 - o qual levou Proust a duelar com o crítico (devido às alusões ao relacionamento íntimo com Lucien Daudet). 
escritor tão jovem. Porém, é preciso. É preciso, até, confessar que esses dons tão variados não se contradizem, mas que, ao contrário, formam um conjunto feliz, brilhante e fácil."

Paul Souday: "Em sua grande obra, o senhor Marcel Proust abraça a história da humanidade ou ao menos a de um século? Não. Ele nos conta suas lembranças de infância. Sua infância, então, foi repleta de eventos extraordinários? De maneira alguma: não lhe aconteceu nada de excepcional... Por outro lado, esse longo volume não se deixa ler com facilidade. Não só ele é compacto, como frequentemente obscuro. Essa obscuridade, na realidade, se deve menos à profundidade do pensamento do que à confusão da elocução [...] as incorreções pululam [...] Visivelmente, os jovens não sabem mais francês. A lingua se decompõe, se transforma em um dialeto informe e desvia rumo à barbárie... Entretanto, o senhor Marcel Proust possui, sem sombra de dúvida, muito talento [...] Há, em suas copiosas narraçôes, algo de Ruskin et de Dickens [...] Parece-nos que o grosso volume do senhor Marcel Proust não é uma composição, e que ele é tão desmesurado quanto caótico, mas que ele contém elementos preciosos com os quais o autor poderia ter feito um pequenino livro sublime".

O caminho sinuoso da obra vai de par com o caminho tortuoso da crítica. De uma forma geral, pode-se dizer que a reação contra os títulos de Proust começa a abrandar a partir da publicação de suas duas traduções - a chamada "era das traduções" (expressão dele próprio) proustiana: La Bible d'Amiens (1904) e Sésame et les lys (1906), dois títulos de Ruskin. Mas também ela testemunha a reação crítica ao trabalho de Proust, em todos os níveis. A começar pela qualidade textual das traduções. É sabido que Proust não traduziu sozinho La Bible d'Amiens e Sésame et les lys. Seus parcos conhecimentos da língua inglesa levaram-no a depender, primeiramente, do auxílio da mãe, que fazia uma versão inicial literal dos textos. A amiga Marie Nordlinger também traduziu longos trechos, mas parece não ter querido qualquer menção à sua colaboração no momento das publicações (Proust agradece, em seu prefácio a $L a$ Bible d'Amiens, o auxílio "pontual” do amigo Robert d'Humières, tradutor de Kipling, e o de Nordlinger, no prefácio de Sésame et les lys). Mas seu desconhecimento da língua inglesa é notório, e será alvo de críticas ferrenhas.

Um exemplo, entre muitos, é revelado pelo próprio Proust, em carta a outro tradutor da obra de Ruskin na França, enquanto prospecta sobre possibilidades de novas traduções do esteta inglês:

Recebi uma carta de um senhor inglês a quem o senhor enviou meus artigos sobre Ruskin ["Ruskin à Notre-Dame d'Amiens" e "John 
Ruskin"]... O seu amigo assinalou um contrassenso na tradução de um trecho da Bible d'Amiens [...]. O senhor me disse que sabia da existência de diversas traduções inéditas de Ruskin. Saberia se, entre elas, se encontra a tradução de Les Pierres de Venise? Tenho a intenção de ir a Veneza e [...] seria um grande alento para mim poder ler in loco Les Pierres de Venise em francês. Naturalmente, se eu fosse traduzir Les Pierres de Venise eu não poderia ler a tradução, que só me atrapalharia. Mas como Les Pierres de Venise não fazem parte das obras que deverei traduzir, não teria nenhum escrúpulo em ler.*

Ainda dentro da ideia de "contrassenso", é também Proust que, em outra carta, reclama da crítica feita pelo diretor da revista Renaissance Latine (que acabara de publicar um trecho inédito da Bible d'Amiens), que debochara de seus conhecimentos da língua inglesa durante uma recepção:

O senhor acabou de ser tão gentil comigo e com os meus Ruskins, que eu não gostaria de parecer o estar repreendendo, mas, ora, considero fantástico, sabendo que trabalho há 4 anos em uma tradução da Bible d'Amiens, que essa tradução vai ser lançada em breve, que ela me custou muito esforço e que lhe dou muita importância [...] [que o senhor diga:] ' $\mathrm{Na}$ verdade, o senhor não sabe inglês, e deve estar cheio de contrassensos'... Uma pessoa que me detestasse e que quisesse aniquilar com uma só palavra o empenho dos meus quatro anos de trabalho executado até em meio à doença... o que ela poderia ter feito de mais grave?*

Outro exemplo é o de Alfonse J. Roche, que, no seu artigo "Proust as a translator of Ruskin", reclama que "Proust, de forma alguma, era bom tradutor. Cometia frequentemente erros crassos. Assim, "'how much do... we spend altogether on our libraries' (parág.32) torna-se, em francês 'nous tous réunis', ao invés de 'ao todo'...”. A lista de incorreções detectadas é longa. ${ }^{3 *}$

Por ser, entre outras coisas, reformador socialista e moralista, os escritos de Ruskin sofreram alguma resistência na França, e a opção pela tradução de seus títulos também foi criticada. Um

\footnotetext{
${ }^{3}$ Proust também será criticado por seu francês: o crítico Paul Souday, em citação já mencionada, disse, quanto ao estilo de Proust: "Essa obscuridade, na verdade, deve-se menos à profundidade do pensamento do que à confusão da elocução [...] as incorreções pululam”; e o escritor René de Boylesve escreve, em carta a Proust, sobre $A$ l'ombre des jeunes filles en fleurs: "Li cem páginas ontem à noite, sem conseguir parar. Eis um fenômeno que não me acomete frequentemente! [Mas...] diga ao seu raio de editor que providencie um maior cuidado com os imperfeitos do subjuntivo! É muito incômodo à leitura... e eu gostaria de acentos circunflexos sobre os ' $\hat{u}$ ' de 'eût' et 'fût' (PROUST, Marcel. 30/10/1919. In: Correspondance. XVII. Paris: Plon, 1987: 444-445).
}

* (PROUST, Marcel. Carta a La Sizeranne, [abril/1900]. In: Correspondance XX. Paris: Plon, 1989: 587.

* (PROUST, Marcel. Carta a Brancovan, [jan/1903]. In: Correspondance III. Paris: Plon, 1979: 219-220.)

* (ROCHE, Alfonse J. “Proust as a translator of Ruskin". In: Modern Language Association, vol.45, n4, s/l, p.12141217, 1930: 1214) 
* (Trecho transcrito pelo organizador da correspondência pessoal de Proust em nota à carta de Proust a Souday, [03/07/1906], sobre a resenha "muito pouco amável" de Maurras, na Gazette de France. PROUST, Marcel. Correspondance VI. Paris: Plon, 1981: 141-142.) artigo de Charles Maurras sobre a publicação de Sésame et les lys expressa essa tendência:

Já que John Ruskin esta na moda, o senhor Marcel Proust tem toda a razão de traduzir Ruskin. Depois da Bible d'Amiens... [ele] acaba de verter para o francês Sésame et les lys. Com símbolos e imagens, como os pré-rafaelitas, não é, porém, um livro menor. Parece-me que o verdadeiro caráter de Ruskin foi alterado na França pelo excesso de delicadeza e de elegância com a qual nos foi apresentado... Os senhores de la Sizeranne, Jacques Bardoux, Marcel Proust são pessoas amáveis e dóceis. Fizeram Ruskin à sua imagem... [mas Ruskin foi] um dos mais severos censores de seu tempo.*

Aqui, Proust não é visto como diletante, mas como alguém "dócil" que "altera" ou deforma o "ácido censor" moralista que é Ruskin, segundo Maurras, para torná-lo palatável ao leitor francês, segundo o seu gosto "delicado e elegante". Não são apenas os três tradutores e ensaístas (La Sizeranne, Bardoux e Proust) que estão sendo criticados nesse artigo, é toda uma política editorial que vinha incentivando a difusão da obra de Ruskin na França.

De um ponto de vista mais abrangente, tanto a política editorial quanto o interesse específico por Ruskin (o fato dele "estar na moda") inserem-se no quadro do combate travado no seio da intelectualidade francesa. Esse combate traduz a busca da identidade artística e literária nacional, deflagrada a partir da Revolução Francesa e que se estende por todo o século XIX: de um lado, os defensores do classicismo francês, e de sua decantada "clareza" de estilo; de outro, os românticos e seus derivados, advogados da elaboração de novas formas de expressão, e que as buscam, inclusive, nos grandes nomes das culturas germânica e anglo-saxã. O interesse por escritores estrangeiros e por sua tradução ganha prestígio, e a obra de Ruskin passa a ter um significado estratégico nesse contexto.

Em 1896, Proust escreveu seu célebre artigo "Contre l'obscurité", em que defende o uso clássico da língua (contra o simbolismo, que ousa, inova e torna as palavras herméticas). No entanto, uma década depois, em seu artigo sobre Nerval, Proust já terá presenciado a ascensão do movimento chamado Renascença Latina, que vai tentar depurar a literatura tanto dos artifícios decadentistas quanto da influência das literaturas estrangeiras - contra o qual o escritor vai se posicionar. Ao longo desses dez anos, Proust 
sofre influência de Ruskin, mas não somente, e inclui no seu "panteão" de obras preferidas, por exemplo,

La Bien-Aimée de Thomas Hardy. Não lhe falta sequer a pequena parcela de grotesco que imbui as grandes obras [...] É melhor nos mais diferentes gêneros, de George Elliott [sic] a Hardy, de Stevenson a Emerson, não há literatura que exerça sobre mim poder comparável ao da literatura inglesa e americana. A Alemanha, a Itália, e, muito frequentemente, a França, me deixam indiferente. Mas duas páginas do Moulin sur la Floss me fazem chorar.*

Os dois primeiros autores citados são, eles próprios, tradutores. E, na França, Baudelaire traduz poemas e contos de Edgar Allan Poe, Mallarmé traduz Poe, Tennyson e ensaios sobre arte e crítica de arte de Whistler, e Nerval traduz Goethe... Esse "poder" das literaturas inglesa e norte-americana exercido sobre Proust passa necessariamente pelo viés da tradução. E a tradução é, forçosamente, um exercício de interpretação e de visão, uma mediação suplementar entre o texto e o leitor, a ser levado em conta na compreensão de uma obra.

Ruskin faz parte, portanto, do elenco de autores estrangeiros buscados pelos franceses à época. O crítico e tradutor Robert de La Sizeranne, considerado como o maior especialista francês em Ruskin até então, mencionado por Maurras em seu artigo, escreve um ensaio particularmente impactante, Ruskin et la religion de la beauté (1897); é dele o epíteto com o qual Ruskin passou a ser conhecido na França: “le Maître de Beautê". O outro nome citado por Maurras é o de Jacques Bardoux, que escreveu outro importante ensaio (Le Culte du beau dans la cité nouvelle. John Ruskin. Poète, Artiste, Apôtre, 1900) que, juntamente com o de La Sizeranne, servirá a Proust em seus comentários às traduções de Ruskin.

Proust passou doze anos dedicando esforços de leitura e tradução aos textos de Ruskin. Por quê? Claro que ele não seguiu um mero fenômeno de moda. Uma das respostas possíveis é o gosto pela polêmica. Até 1896, Proust vinha sendo visto como um diletante. Tornar-se uma "autoridade" em Ruskin lhe permitiria aprofundar sua erudição e conhecimento, e conferir-lhe uma reputação intelectual mais respeitada. Proust vai, então, penetrar no domínio já consolidado de La Sizeranne, e lançar-se como "rival".

Isso ficará explícito nos comentários críticos que antecedem e permeiam a segunda tradução de Proust, Sésame. No artigo "John Ruskin” (que integra o preâmbulo à tradução), Proust vai, sobre-
* (PROUST, Marcel. Carta ao amigo e diplomata Robert de Billy, [março] 1910. In: Correspondance $X$. Paris: Plon, 1986: 54-55.) 
* (RUSKIN, John. Sésame et les lys. Canadá: Livre Electronique de Project Gutemberg, [1906]; s/p.) tudo, combater a visão de que Ruskin fosse um diletante, a qual se deve em grande parte, na França, ao ensaio já citado de La Sizeranne. O texto revela ser um verdadeiro "Contre La Sizeranne".

Além dessa abordagem geral antagonista, Proust dedica duas notas inteiramente a um ataque direto ao ensaio de La Sizeranne. $\mathrm{Na}$ nota 30, lê-se a denúncia ao que considera o "domínio" (como que territorial) ou feudo estabelecido pelo ensaísta:

O Ruskin do senhor de la Sizeranne. Ruskin tem sido considerado, até hoje, muito ajustadamente, como domínio pessoal do senhor de la Sizeranne e, se tento, por vezes, aventurar-me por suas terras, certamente, não é por desconhecer ou para usurpar-lhe os direitos, que não se limitam ao de usucapião. No momento de entrar nesse assunto, o magnífico monumento que por ele erguido a Ruskin domina por toda a parte, e, portanto, eu lhe devia render homenagem e pagar tributo.*

Na nota 31, a crítica é ainda mais clara, em meio a comentário a outros ensaios já editados sobre Ruskin:

O belo esforço do senhor Bardoux não impede que se pense que o livro do senhor de la Sizeranne era perfeito demais dentro dos limites que $o$ autor se impusera, por não ter nada a perder nessa concorrência e nesse estímulo que parece se produzir no domínio de Ruskin... Os senhores Bardoux e Brunhes deslocaram o ponto de vista e, assim, renovaram o horizonte. Guardadas as devidas proporçōes, foi o que eu tentei fazer, aqui mesmo, algum tempo atrás.*

O livro de La Sizeranne é qualificado como "perfeito demais" e limitado, a um só tempo, o que é, evidentemente, algo da ordem da ironia. O essencial da disputa então travada contra a maior autoridade sobre Ruskin da época concentra-se na questão da beleza como sendo o eixo da "religião de Ruskin". Proust diz que não quer contradizer o "sistema de M. de la Sizeranne", mas que ele poderia ficar "diminuído, no entender dos leitores, mediante uma interpretação falsa". Para corrigir qualquer erro de interpretação por parte do leitor, sentencia: "a principal religião de Ruskin foi a religião tout court": o sentimento religioso de Ruskin é o "centro de gravidade da estética ruskiniana”, e determina o seu sentimento estético, que é "profundo" e "original", e o impede, "ao contrário do que se pensou muitas vezes, de imiscuir às suas impressões diante das obras de arte qualquer artifício de raciocínio que lhes fosse estranho. De modo que quem vê nele um moralista e um apóstolo que admira 
na arte o que não é arte, se engana”. Está claro que "que se pensou muitas vezes" refere-se à interpretação dada por La Sizeranne.

O tom categórico de Proust lhe é possível após ter sido aclamado como voz crítica avalizada sobre Ruskin por ocasião da primeira tradução: La Bible d'Amiens foi aclamada como uma contribuição importante aos estudos sobre o esteta e a estética em geral (apesar das críticas a seus erros de língua - francesa - e à sua compreensão limitada do inglês). Dessa recepção há vários testemunhos, mas, talvez, o mais significativo seja o de Henri Bergson (que foi professor de Proust na Ecole des Sciences Politiques). Em carta a Proust, o filósofo acredita que a tradução de La Bible d'Amiens

exprime la quintessence même de l'œuvre de Ruskin... Je crois, comme vous, que chaque art se propose de rendre certains états d'âme qui seraient inexprimables en tout autre langage: c'est la raison d'être de cet art. Si la peinture était belle "dans la mesure où les idées qu'elle traduit en images sont indépendantes de la langue des images”, la peinture serait inutile.*

Nessa primeira correspondência, Bergson apoia e se solidariza com a concepção estética de Proust, e, implicitamente, com a crítica feita por Proust ao que, no artigo "John Ruskin”, considera (até então) o único erro de Ruskin: dizer que "um quadro é belo na medida em que as ideias que ele traduz em imagens são independentes da língua das imagens". E afirma que Proust captou a "quintessência” da obra de Ruksin - ideia que desenvolve em seguida.

Uma segunda carta de Bergson não é reproduzida na íntegra por Kolb, o organizador da correspondência pessoal de Proust, mas este insere, em nota, o texto do comentário crítico de Bergson, apresentado ao Institut de France, a que ela se refere:

Tenho a honra de apresentar à Academia, em nome de Marcel Proust, a tradução, acompanhada de notas e prefácio, que ele acaba de fazer da La Bible d'Amiens de Ruskin. O prefácio é uma importante contribuição à psicologia de Ruskin. O senhor Marcel Proust nos rememora os julgamentos contraditórios expressos sobre o esteta Ruskin. Já foi dito que Ruskin era um idealista e que ele era um intelectual, que ele suprimia o papel da imaginação na arte, por atribuir uma importância exageradamente grande à ciência, e que ele arruinava a ciência ao atribuir um papel excessivamente grande à imaginação, que ele era um esteta puro, pois só amava a beleza, e que ele não era um artista, pois misturava à sua apreciação da beleza considerações estranhas à estética. O senhor Marcel Proust retraça a origem de todas essas divergências. Ruskin foi, antes de tudo, uma alma religiosa. Sua estética é a de um homem que crê que o poeta e o
* (PROUST, Marcel. Correspondance XXI. Paris: Plon, 1990: 622; grifo meu.) 
* (PROUST, Marcel. 29/05/1904. In: Correspondance IV. Paris: Plon, 1980: 137-138; os destaques são meus.) artista se limitam a transcrever uma mensagem divina. Então, ele é um idealista do mais alto grau, mas é também realista porque, para ele, a matéria não passa de uma expressão do espírito... De onde ele viver numa arte, por excelência, cristã. De onde, também, ele ter amado profundamente, compreender e levar a compreender a arquitetura, a escultura e a pintura da Idade Média. Nesse sentido, o livro que Ruskin escreveu sobre a catedral de Amiens é um dos que mais nos fazem penetrar na intimidade de seu pensamento. O senhor Marcel Proust o traduziu em uma língua tão animada e original que não se acredita, ao ler o livro, estar diante de uma tradução. Ele acrescenta notas em que encontramos numerosas relações entre La Bible d'Amiens e outras obras do mesmo autor.*

Do ponto de vista de Bergson, Proust revela aspectos psicológicos do esteticismo de Ruskin que dão conta de parte das contradiçôes que se detectam na obra. Insistindo sobre o aspecto religioso do pensamento de Ruskin (que é o ponto axial da divergência entre Proust e La Sizeranne), ressalta o caráter de escriba (da palavra de Deus) conferido por Ruskin ao artista, esvaziando a relevância das polêmicas quanto à categorização político-ideológica de seu trabalho. Bergson elogia a qualidade linguística da tradução e a escolha da obra como representativa da psicologia ou da "intimidade" do pensamento do esteta. De certa forma, o filósofo reproduz em resumo os prefácios ao texto traduzido, mas como que aprova a edição da obra, pela escolha do texto e pela sua explanação por via de notas numerosas. $\mathrm{O}$ fato de Bergson ter dado um parecer positivo da tradução do livro na Academia de Ciências Morais e Políticas já gabarita, diante do meio artístico, intelectual, e também acadêmico, o trabalho realizado por Proust.

Talvez a observação mais interessante feita às traduções empreendidas por Proust seja a do crítico André Beaunier em sua resenha do Figaro sobre a publicação de Sésame et les lys, que exemplifica bem a ambiguidade da recepção a Proust feita por seus contemporâneos:

Atento ao menor detalhe da frase, e como que ao seu sotaque... [Marcel Proust] é fiel e consegue escrever, em excelente francês, du Ruskin. É o modelo de uma tradução bem feita, obra prima de inteligente docilidade, impressionante façanha.

Marcel Proust gosta muito de Ruskin... Talvez ele goste menos do que imagina. De toda forma, tem veleidades de independência. Depois de ter seguido esse danado desse homem durante algum tempo, ele se pergunta aonde será levado. Por isso, continua a traduzir com submissão meritória; mas indica seus escrúpulos ao pé da página: e 
suas notas, numerosas, abundantes, variadas, são redigidas com os mesmos espírito e ciência. Trata-se de marcar claramente que não se tem a mesma opiniāo que o autor, e que, porém, o autor não está completamente errado... Para o senhor Marcel Proust, é a oportunidade de indicar mil relaçôes engenhosas e de contar anedotas, de fazer gracejos, e de se revelar um encantador ensaista.

Ele lê Ruskin como Montaigne lia Plutarco: ele "essaye", "ensaia" ao contato de outro pensamento, seu pensamento [...] e, imperceptivelmente, consegue dar conta de si mesmo. É o jogo de um moralista delicado...*

Beaunier começa dizendo que a tradução, em termos de domínio da língua, está bem feita, e que ele escreve "du Ruskin", em estilo ruskiniano, em francês. E que se trata de um "modelo de tradução" por ser uma "obra-prima de inteligente docilidade". A crítica é evidente: Proust "gosta muito de Ruskin", talvez demais, para o crítico, pois realiza uma segunda tradução desse mesmo autor polêmico; denuncia o que considera serem "veleidades de independência", as críticas iniciais que Proust faz à obra, numa tentativa clara de desvincular seu pensamento do de Ruskin, em que afirma "não ser da mesma opinião, mas que Ruskin tem razão" - a independência de pensamento já é questionada aqui, em 1906, e será uma questão indigesta para grande parte dos críticos da obra ulterior de Proust, como se verá logo a seguir.

Ao rotular Proust de "moralista delicado" (chegando a compará-lo a Montaigne), Beaunier reconhece que Proust conseguiu, através de suas notas e comentários ao texto do esteta inglês, emitir suas próprias opiniōes sobre estética e filosofia, e que revelou ser um bom ensaísta. Esse reconhecimento constitui uma etapa importante na alteração da imagem de Proust junto a seus pares, e preparara caminho à recepção diferenciada dos vários volumes da Recherche. Esse fato é de grande relevância, pois é também no prefácio a Sésame que Proust cunha e define a sua prosa poética nostálgica, tal como será lida, como que em decalque, em vários trechos de "Combray" e em outros momentos de devaneio lírico ao longo da Recherche - e que passa ser uma marca de sua escritura a partir de então.

A afirmação de que a tradução feita por Proust é "modelar" não deixa de ser um contrassenso em si, pois a "tradução proustiana" não se limita à versão de uma língua a outra. Trata-se de uma anotação extensiva, uma crítica constante e recorrente realizada paralelamente à redação do texto (em que, aliás, se constata
* (PROUST, Marcel. 14/06/1906. In: Correspondance VI. Paris: Plon, 1981: 118-119; grifos meus.) 
forte interferência sobre a forma por parte do tradutor). A tradução proustiana apresenta comentários detalhados e sistemáticos ao conteúdo do texto original (em ostensiva intervenção sobre esse conteúdo, visando, segundo o próprio tradutor em notas explicativas, balizar e orientar a leitura a ser feita do texto, na França). Esses comentários resultam em uma tradução peculiar, pois se tornam, na França, mais relevantes do que o texto original. Embora Proust até tenha tentado se manter fiel à intenção de Ruskin (o que se constata através das inúmeras consultas a amigos anglófonos que se encontram em sua correspondência pessoal), não realizou o que preconizam escolas de tradução mais ortodoxas, segundo as quais o tradutor deve se apagar diante do autor. Proust rivalizou com Ruskin nos dois livros que traduziu (além de rivalizar com os demais estudiosos e tradutores da obra ruskiniana à época); criou seu próprio mosaico de erudição e o sobrepôs ao de Ruskin. Criou, sobretudo, uma tradução híbrida, que mistura ensaio, crítica, autobiografia e tradução, impregnando-se do hibridismo do próprio texto traduzido (que mistura ensaio, crítica, imprecação e autobiografia ao baralhamento geral do texto).

Esse hibridismo iniciado na Bible d'Amiens será redimensionado e intensificado no prefácio de Sésame et les lys, no qual o aspecto autobiográfico acaba imperando sobre a apresentação crítica da obra, e em que se antevê o texto "entre-vários-gêneros" que constituirá a obra ficcional ulterior de Proust, na qual romance, ensaio e autobiografia se mesclam e fundem, confundem os leitores, e iludem os críticos.

Não é sem interesse o fato de que os críticos franceses, até hoje, remoem com certa indigestão a importância de Ruskin na trajetória de Proust. Não são poucas as escamoteações e as escusas. Muitos são pródigos em estudos intertextuais, e, evidentemente, há quem examine a relação entre os seus escritos e os de Ruskin. Mas nem sempre há acordo quanto à importância de Ruskin na formação ou informação dos conceitos de estética, e até no estilo, de Proust (enquanto os críticos franceses que o mencionam tendem a diminuir, ou mesmo ignorar, qualquer ascendência sua sobre Proust, os críticos anglófonos, por suposto, tendem a aumentá-la).

Citando apenas alguns exemplos mais significativos, pode-se destacar, inicialmente, a opinião de Bernard de Fallois, um dos organizadores da edição da obra proustiana pela Gallimard, e que, portanto, expressa uma avaliação ou "versão oficial" da editora. Em 
seu prefácio a Contre Sainte-Beuve, ele afirma que "Ruskin marcava [...] uma regressão [“un repli”], um trabalho de erudição que o desviava de sua atividade profunda".* Outra voz que exprime a perspectiva partilhada pela Gallimard e a maioria dos críticos franceses é a de Jean-Yves Tadié, que, na sua introdução à edição Pléiade de A la Recherche du Temps Perdu, afirma que Proust fez "tábua rasa do passado e de Ruskin, a quem disse adeus" ao começar a redação da Recherche.*

Outro grande especialista, o norte-americano Philip Kolb, organizador dos 21 volumes da correspondência pessoal de Proust, publicou um artigo, "Proust et Ruskin: nouvelles perspectives", em que faz uma ressalva quanto à influência de Ruskin (relativizando-a, portanto) à luz dessa correspondência, e em que diz: "sempre houve entre Proust e a obra de Ruskin uma espécie de barreira linguística"* imposta pelos parcos conhecimentos de Proust do idioma inglês e pela intermediação dos diversos amigos convocados a realizarem contribuiçōes e revisões às suas traduções. Kolb sintetiza sua opinião sobre a influência do esteta:

quanto às ideias de Ruskin que se refletem na obra de Proust, não é seguro que este tenha tomado de empréstimo ao mestre inglês o conceito de arte como visão poética do universo, a ideia de que um artista deve encontrar em si mesmo a matéria de sua obra, e outras que se atribuem a Ruskin. Tais ideias eram, sem dúvida, moeda corrente à época.*

Seria difícil estabelecer fronteiras entre o que é pessoal e original, e o que "é moeda corrente". Difícil e inútil. O próprio caráter enciclopédico da obra de Proust, que ostenta e assume os seus inúmeros antecessores e influências, citando-os ora explicitamente, ora por alusão, nos mais diversos registros e das mais variadas maneiras - da literal à deturpada ou irônica, ou ainda às avessas -, rejeita esse esforço de vã mensuração: rastrear e pesar o aporte de John Ruskin à obra de Marcel Proust, como vem ocorrendo até os dias de hoje entre os críticos dos dois lados da Mancha, não deixa de ser a reedição fabulária de uma velha rivalidade entre dois reis (em citação e encenação involuntárias do incipit de "Combray"). ${ }^{4}$

\footnotetext{
${ }^{4}$ Embora os exemplos da visão antagônica sejam inúmeros, pode-se mencionar um dos mais significativos, por emanar de uma das maiores especialistas no estudo comparativo entre Ruskin e Proust, Cynthia Gamble. Ela escreveu o artigo de título sugestivo "Zipporah: a Ruskinian enigma appropriated by Marcel Proust" (Em Word \& Image, Londres, vol.15, n4, 1999: 381-394), em que explica como
}

* (PROUST, Marcel. Contre Sainte-Beuve. Paris: Gallimard, 1994: 16)

* (TADIÉ, Jean-Yves. Introduction. In: PROUST, Marcel. A la Recheche du Temps Perdu, Vol. I, Ed. Pléiade. Paris: Gallimard, p.ix-cvii, 1987: xxiv.)

* (KOLB, Philip. Proust et Ruskin: nouvelles perspectives. In: Cahiers de l'Association Internationale des études françaises, ${ }^{\circ} 12$, Michigan: Belles Lettres, 1960, p. 261-273: 262.)

* (Ibidem: 266.) 
Contudo, entre influências particularizadas e afinidades contemporâneas, maiores ou menores, o fato é que a "fase ruskiniana" de Proust compreende os anos iniciais de leitura esporádica de trechos da obra de Ruskin (de 1893 a 1899), durante os quais Proust esboça o seu inacabado Jean Santeuil (1895-1899), e, mais consistentemente, os subsequentes anos de intensos esforços de tradução que empreenderá de La Bible d'Amiens (1899-1904) e de Sésame et les lys (1904-1906). Trata-se, portanto, de um período de doze anos, que não podem ser assimilados a um mero exercício de erudição, inclusive por constituírem, grosso modo, o intervalo entre as publicações de Les Plaisirs et les Jours e o início da escritura do ensaio romanceado Contre Sainte-Beuve (1907), interrompido e incorporado à redação de $A$ la Recherche du Temps Perdu (começada em 1909).

Ao traduzir a "intimidade" e a "quintessência" do pensamento de Ruskin (segundo Bergson), Proust traduz, sobretudo, sua visão pessoal da visão de Ruskin. Esta, como um caleidoscópio, se reflete, fragmenta, multiplica e espraia pelos seus inúmeros comentários, nos quais Proust capta reflexos e vislumbres da obra ruskiniana densa, intensa, complexa e disputada, e lhes dá destaque, relevo, e outra dimensão.

Proust conhece Ruskin, inicialmente, por meio de traduçôes, e, em seguida, no original, em parte pelo viés da assistência de amigos e da mãe. Sua visão da visão de Ruskin é intermediada, enviesada, oblíqua. Até que, no fazer da tradução, Proust se apropria do texto de Ruskin, transformando-o em um texto (em) francês, refazendo-o, às vezes, por completo (em tradução, portanto, nada modelar), e impondo, em última instância, a sua leitura da obra. Suas notas e observações direcionam o entendimento de seu leitor, estabelecem caminhos claros para elucidar a obscuridade do texto, definem um traçado lógico no labirinto das linhas e entrelinhas, estabelecem conexôes com outras obras do autor, acrescentam informaçôes de outros autores, identificando alusões, especificando citações, ordenando, à sua maneira, o universo desses dois pequenos livros que, aos seus olhos, condensam a gigantesca riqueza do pensamento de Ruskin, e servem de ponte para ele (esse procedimento crítico dará início à crítica temática, que se desenvolverá no

a obsessão de Ruskin pela imagem da Zéfora de Botticelli foi integrada e transfigurada por Proust em sua obra. 
século XX). O caleidoscópio (móvel), apropriado e decodificado, transforma-se em mosaico (fixo).

Ao transferir " $d u$ Ruskin" à língua francesa, Proust passa a expressar e a ver reconhecidas suas próprias versão e visão, não só de Ruskin e de seus temas, mas de todo um mosaico de temas que, enquanto notas e adendos esparsos e fragmentários, servem de apoio às traduções, mas que, com o tempo, virão a ser o esteio invisível porém sensível de sua obra catedral. Mas essa é uma longa estória.

Luciana Persice Nogueira tem pós-doutorado em Língua e Literaturas de Língua Francesa pela UFRJ e é professora da Aliança Francesa. Principais artigos publicados: "Proust e sua visão de Ruskin: tradução e revelação da passagem entre les deux côtés", Revista Interfaces, Vol.1, 2011, p.24-43, "L'Enluminure dans Le Nom de la Rose: symbolique et pouvoir du rire", Les Cahiers du GRIMH, Lyon 2, Bron, p. 317/325, 2006, e "A Retórica do contador e o teatro da praça em Ben Jelloun", Terceira Margem, Rio de Janeiro, no 9, p. 124/138, 2003. E-mail: <luciana.persice@yahoo.com.br> 